\title{
WELDABILITY AND WELDING METALLURGY OF HAYNES 282 ALLOY
}

\author{
Jeremy L. Caron \\ Haynes International, Inc. \\ Kokomo, IN 46094-9013, USA
}

Keywords: Weldability, 282 Superalloy, Varestraint, Hot Ductility, Heat-Affected Zone

\begin{abstract}
Testing was conducted to determine the weldability of 282 alloy, specifically focused on its weld hot cracking susceptibility, namely, weld solidification and heat-affected zone (HAZ) liquation cracking. Weld solidification cracking susceptibility was evaluated through Varestraint testing. Based on total and maximum crack length measurements for two different production heats of 282 alloy containing nominal $(0.005 \mathrm{wt} \%)$ and low $(0.003 \mathrm{wt} \%)$ levels of boron, 282 alloy exhibits excellent solidification cracking resistance. The nominal boron heat exhibited higher crack lengths, demonstrating the adverse effect of boron on solidification cracking resistance. However, cracking susceptibility was still lower than many other high-temperature Ni-base alloys. The Gleeble hot-ductility test was utilized to determine the HAZ liquation cracking temperature range for 282 alloy in the age-hardened condition. These results suggest that 282 alloy has excellent resistance to HAZ liquation cracking. Hot-ductility test samples were characterized in order to understand HAZ microstructure evolution. The effect of postweld heat treatment on weld metal microstructure was also determined. Overall, the results indicate that 282 alloy possesses a unique combination of material properties and weldability.
\end{abstract}

\section{Introduction}

HAYNES $^{\circledR} 282^{\circledR}$ alloy (UNS N07208) is a wrought $\gamma^{\prime}$-strengthened Ni-base superalloy developed for high-temperature structural applications, mainly in aero- and land-based gas turbine engines [1,2]. 282 alloy has excellent creep strength in the temperature range of 1200 to $1700^{\circ} \mathrm{F}$ (649 to $927^{\circ} \mathrm{C}$ ), surpassing that of Waspaloy and similar to that of R-41 (René 41) alloy. This level of creep strength was achieved with a significantly lower volume fraction of the strengthening $\gamma^{\prime}$ phase compared to both Waspaloy and R-41 alloy.

The nominal chemical composition of 282 alloy is provided in Table I. Its properties are developed through a two-step age-hardening heat treatment consisting of $1850^{\circ} \mathrm{F}$ $\left(1010^{\circ} \mathrm{C}\right) / 2 \mathrm{hr} / \mathrm{Air}$ Cooled $(\mathrm{AC})+1450^{\circ} \mathrm{F}\left(788^{\circ} \mathrm{C}\right) / 8 \mathrm{hr} / \mathrm{AC}$. The first step at a higher temperature results in the grain boundary precipitation of $\mathrm{Cr}$-rich $\mathrm{M}_{23} \mathrm{C}_{6}$ carbides. The second step of the heat treatment results in the formation of gamma-prime $\left(\gamma^{\prime}\right)$ precipitates, which are spherical with an average diameter of approximately $20 \mathrm{~nm}$.

Table I. Nominal Chemical Composition of 282 Alloy in Weight Percent

\begin{tabular}{|c|c|c|c|c|c|c|c|c|c|c|}
\hline $\mathrm{Ni}$ & $\mathrm{Cr}$ & $\mathrm{Co}$ & $\mathrm{Mo}$ & $\mathrm{Ti}$ & $\mathrm{Al}$ & $\mathrm{C}$ & $\mathrm{B}$ & $\mathrm{Fe}$ & $\mathrm{Mn}$ & $\mathrm{Si}$ \\
\hline $57^{* *}$ & 20 & 10 & 8.5 & 2.1 & 1.5 & 0.06 & 0.005 & $1.5^{*}$ & $0.3^{*}$ & $0.15^{*}$ \\
\hline
\end{tabular}

HAYNES and 282 are registered trademarks of Haynes International, Inc. 
The American Welding Society (AWS) definition of weldability is: "the capacity of material to be welded under the imposed fabrication conditions into a specific, suitably designed structure performing satisfactorily in the intended service" [3]. This definition not only includes the capacity to join components of the alloy, but also refers to service performance. Weldability is a major concern for many Ni-base superalloys since they are required to perform adequately in some of the most demanding environments. Prior to being placed into service, these alloys must be fabricated, which oftentimes involves welding. 282 alloy is normally welded in the annealed condition and subjected to the age-hardening heat treatment after welding. A full solution anneal (SA) after welding and prior to age hardening is normally suggested, but is not required in order to develop suitable properties. The mechanical properties of 282 welds have been established for both the gas-metal arc welding (GMAW) and gas-tungsten arc welding (GTAW) processes. Representative data can be found elsewhere [4]. A positive feature of 282 alloy is that the $0.2 \%$ yield strength of all-weld-metal (AWM) samples in the age-hardened condition is typically equivalent to base metal (BM) samples in a similar age-hardened condition. As such, there is relatively consistent strength across the various regions of the weldment and transverse weld tensile samples often exhibit failure in the BM/HAZ region, which is viewed favorably from a weldability standpoint. Furthermore, based on all testing to date, the creep-rupture strength of 282 AWM exceeds that of the BM in a similar age-hardened condition [4]. In another study, 282 alloy exhibited good weldability after long-term thermal exposure and rejuvenation of the microstructure after postweld SA and age hardening [5].

Ni-base $\gamma$-strengthened alloys are mainly susceptible to three different forms of weld cracking: weld solidification cracking, heat-affected zone (HAZ) liquation cracking, and strain-age cracking. The strain-age cracking susceptibility of 282 alloy has been carefully studied by Metzler through the use of controlled heating-rate tensile (CHRT) tests [6, 7]. The results of 282 alloy were compared to other $\gamma^{\prime}$-strengthened Ni-base superalloys, such as R-41, Waspaloy, and 263 alloys (Figure 1). 282 alloy exhibited better strain-age cracking resistance, as measured by CHRT elongation, than R-41 or Waspaloy alloys, approaching that of 263 alloy. The good strain-age cracking resistance of 282 alloy based on CHRT testing is in harmony with all fabrication history to date and is attributed to its relatively sluggish $\gamma^{\prime}$ precipitation kinetics. Building upon the prior work of others, the goals of this study were to evaluate the weld hot cracking susceptibility, namely, weld solidification and HAZ liquation cracking susceptibilities, of 282 alloy in order to develop a more complete understanding of its overall weldability.

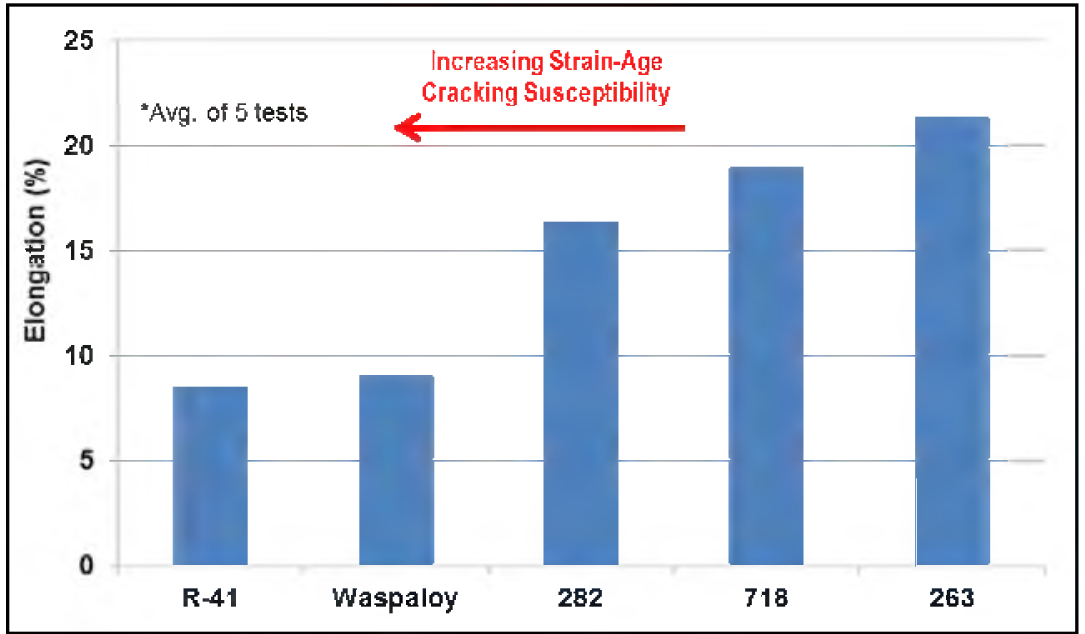

Figure 1. CHRT test results at $1450^{\circ} \mathrm{F}\left(788^{\circ} \mathrm{C}\right)$; adapted from Metzler [6]. 


\section{Experimental Procedure}

\section{Varestraint Testing}

The Variable Restraint, or "Varestraint", weldability test is a well-established test to evaluate weld hot cracking susceptibility [8]. It has been used extensively to measure the weld solidification cracking susceptibility of Ni-base alloys [9]. During the test, a bending strain is applied to a sample during autogenous GTAW, which induces cracking in the partially solidified metal at the trailing edge of the weld pool. The level of applied strain can be varied with the use of die blocks with different radii. Susceptibility is quantified as the total crack length (TCL) or maximum crack length (MCL), which allows a ranking of alloys in terms of cracking resistance. TCL represents the summation of all crack lengths measured; MCL represents the longest crack measured. Duplicate subscale longitudinal Varestraint tests were performed with $63.5 \mathrm{~mm}$ ( $2.5 \mathrm{in}$ ) and $101.6 \mathrm{~mm}$ (4.0 in) radius die blocks to produce $2.5 \%$ and $1.6 \%$ augmented strain, respectively. The welding parameters were: welding current $=70 \mathrm{~A}$, arc length/gap $=0.94 \mathrm{~mm}$ travel speed $=11.4 \mathrm{~cm} / \mathrm{min}$, shielding gas $=100 \% \mathrm{Ar}$, and bending stroke rate $=12.7 \mathrm{~cm} / \mathrm{s}$. To study the effect of boron content, two production heats of 282 alloy sheet $(3.2 \mathrm{~mm}$ thickness) containing nominal $(0.005 \mathrm{wt} \%)$ and low $(0.003 \mathrm{wt} \%)$ levels of boron were tested. While boron is intentionally added to 282 alloy to improve grain boundary strength for enhanced creep resistance, it is an element known to have a strong deleterious effect on weld solidification cracking resistance. There were not significant differences in the concentrations of any of the other elements analyzed for the two heats. In addition to 282 alloy, several comparable alloys of nominally $3.2 \mathrm{~mm}$ thickness were also tested as a reference. All of the alloys were tested in their standard mill-annealed condition. After testing, the sample surfaces were buffed with a light abrasive fiber wheel just enough to remove the surface oxide. Cracks were measured with a stereo microscope at 20-50x magnification.

\section{Hot-Ductility Testing}

The hot-ductility test was utilized to evaluate the HAZ liquation cracking susceptibility of 282 alloy. The hot-ductility test simulates the metallurgical degradation that occurs during a weld thermal cycle and provides a measure of the ductility that would be exhibited by an alloy at high temperatures in the HAZ. Ductility is a key component of overall weldability because weld cracking is often associated with an exhaustion of available ductility. To determine the overall elevated-temperature ductility of an alloy, both on-heating and on-cooling tests are performed. Tests were conducted with the GLEEBLE ${ }^{\circledR} 3800$ thermal-mechanical simulator using $6 \mathrm{~mm}$ diameter by $100 \mathrm{~mm}$ length solid bar samples of 282 alloy in the fully age-hardened condition. The on-heating tests were conducted by heating the samples to the test temperature at a linear rate of $200^{\circ} \mathrm{F} / \mathrm{s}\left(111^{\circ} \mathrm{C} / \mathrm{s}\right)$ and then pulling the sample to failure at $2 \mathrm{in} / \mathrm{s}(50.8 \mathrm{~mm} / \mathrm{s})$. For oncooling tests, the samples were heated to the desired peak temperature and then cooled to the test temperature at $50^{\circ} \mathrm{F} / \mathrm{s}\left(28^{\circ} \mathrm{C} / \mathrm{s}\right)$ before being pulled to failure at $2 \mathrm{in} / \mathrm{s}(50.8 \mathrm{~mm} / \mathrm{s})$. The nilstrength temperature (NST) was determined by heating at a linear rate of $200{ }^{\circ} \mathrm{F} / \mathrm{s}\left(111^{\circ} \mathrm{C} / \mathrm{s}\right)$ under a small force of $50 \mathrm{lbf}(23 \mathrm{~kg})$. Following testing, the diameter of the fracture surfaces were measured and compared to the original diameter to determine the percent reduction-in-area (\%RA). Single tests were conducted at each test temperature. 


\section{$\underline{\text { Microstructure Characterization }}$}

After testing, selected samples were submitted for metallographic analysis. After mounting and polishing, electrolytic etching was performed in a solution consisting of $5 \mathrm{~g}$ oxalic acid $\left(\mathrm{H}_{2} \mathrm{C}_{2} \mathrm{O}_{4}\right)$ mixed with $95 \mathrm{ml}$ reagent grade hydrochloric acid $(\mathrm{HCl})$. To reveal the $\gamma^{\prime}$ precipitates for scanning electron microscopy (SEM), samples were electrolytically etched with chromic acid $\left(\mathrm{H}_{2} \mathrm{CrO}_{4}\right)$ made from $15 \mathrm{~g}$ of crystalline chromium oxide $\left(\mathrm{CrO}_{3}\right)$, plus $10 \mathrm{~mL}$ of concentrated sulfuric acid $\left(\mathrm{H}_{2} \mathrm{SO}_{4}\right)$ dissolved in $150 \mathrm{~mL}$ of $85 \%$ phosphoric acid $\left(\mathrm{H}_{3} \mathrm{PO}_{4}\right)$ [10]. The etchant also reveals the presence of $\gamma^{\prime}$ as a dark tint when examined in the light optical microscope.

\section{Results and Discussion}

\section{$\underline{\text { Varestraint Test Results }}$}

Varestraint test results for 282 and comparable alloys are shown in Figures 2 and 3. At the lower strain level, the 282 alloy heat with $0.003 \mathrm{wt} \% \mathrm{~B}$ exhibited smaller TCL and MCL values than the other alloys tested. At higher strain, both heats of 282 alloy exhibited a significant increase in TCL and MCL. At both strain levels, the $0.005 \mathrm{wt} \% \mathrm{~B}$ heat exhibited higher crack lengths than the $0.003 \mathrm{wt} \% \mathrm{~B}$ heat, demonstrating the adverse effect of boron on solidification cracking resistance. However, with the exception of 263 alloy, both heats of 282 alloy exhibited lower TCL and MCL values than the other alloys tested. When compared to 718 alloy, the nominalboron heat of 282 alloy exhibited approximately half of its crack length values.

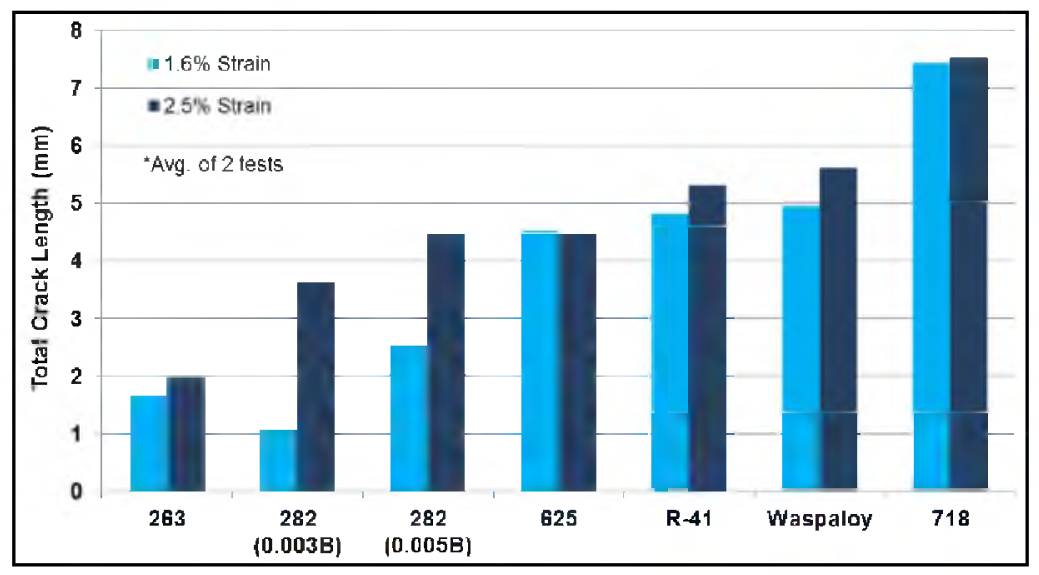

Figure 2. Total crack length measurements from subscale longitudinal Varestraint tests

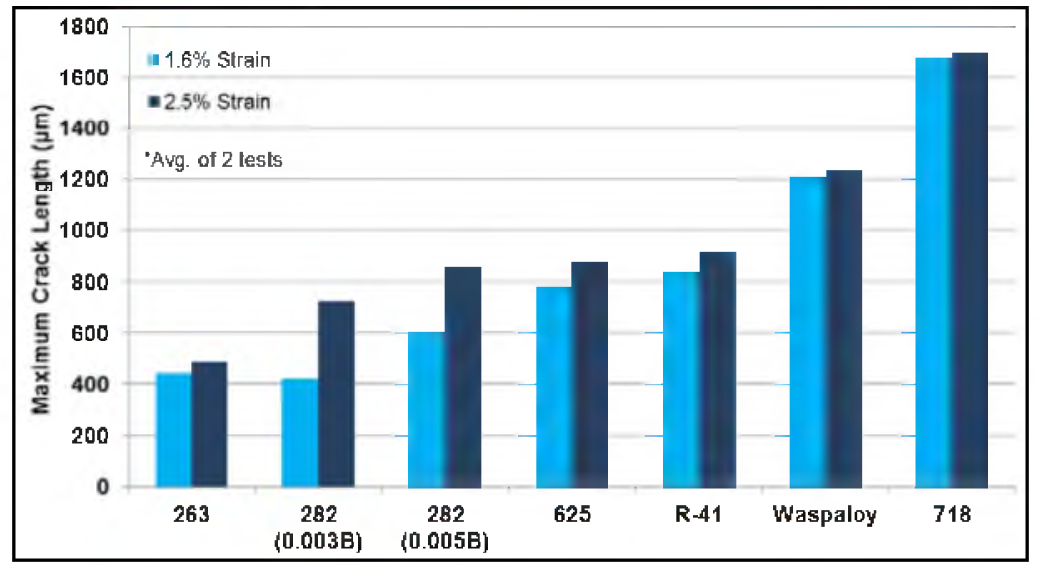

Figure 3. Maximum crack length measurements from subscale longitudinal Varestraint tests 
The Varestraint results suggest that the weld solidification cracking resistance of 282 alloy is sensitive to boron concentration. The results clearly show that while the $0.005 \mathrm{wt} \% \mathrm{~B}$ heat exhibited good solidification cracking resistance, lower boron content resulted in even better resistance. For this reason, the boron levels in 282 alloy are carefully controlled. When comparing crack lengths at the two different levels of strain, the results also suggest that 282 alloy may be more sensitive to higher weld restraint than the other alloys. It is also possible that the other alloys approached or reached their Varestraint saturated strain, whereby increases in the strain level result in negligibly different crack lengths. The combination of higher strain and higher boron would undoubtedly be expected to lead to greater solidification cracking susceptibility. Actually, solidification cracking has been reported during fabrication of highrestraint weld geometries involving 282 filler metals containing higher-than-nominal boron contents. However, based on the results of this study, 282 alloy exhibited better solidification cracking resistance than R-41, Waspaloy, and 718 alloys. While there are other factors contributing to their higher solidification cracking susceptibility compared to 282 alloy, these three alloys all contain intentional additions of boron nominally in excess of that contained in 282 alloy.

\section{$\underline{\text { Weld Metal Solidification and Microstructure }}$}

The weld solidification cracking resistance of 282 alloy is related to the weld metal solidification sequence. Based on SEM characterization, the as-solidified weld metal microstructure of 282 alloy mainly consists of fcc $\gamma$ phase with discrete (Ti,Mo)-rich $\mathrm{MC}$ carbide formed along the solidification grain boundaries (Figure 4). In addition, Ti(C,N) particles and a small amount of $\mathrm{Cr}$-rich $\mathrm{M}_{23} \mathrm{C}_{6}$ carbides have been identified in the as-welded condition. While the Ti(C,N) particles are presumed to form during initial solidification, the $\mathrm{M}_{23} \mathrm{C}_{6}$ carbides may have formed in the solid-state upon cooling or during reheating of a multipass weld. The formation of $\gamma / \gamma^{\prime}$ eutectic during terminal solidification, which is associated with solidification cracking susceptibility in many $\gamma^{\prime}$-strengthened alloys, has not been observed in 282 weld metal. Spherical $\gamma^{\prime}$ precipitates of a size comparable to that in age-hardened base metal $(\sim 20 \mathrm{~nm})$ were identified in the intragranular regions of as-welded 282 weld metal (Figure 4b). However, these precipitates are presumed to have formed in the solid-state upon cooling
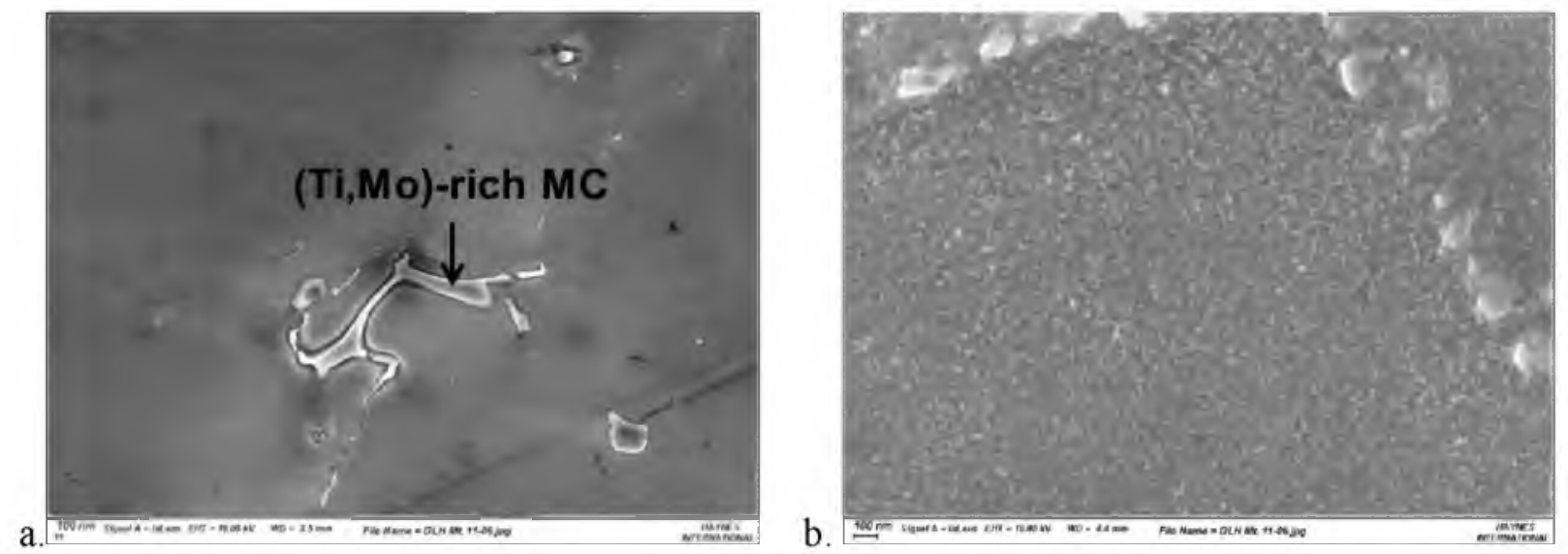

Figure 4. SEM micrographs of 282 weld metal in the as-welded condition. The left micrograph (4a) exhibits the (Ti,Mo)-rich MC eutectic phase. The right micrograph (4b) shows intragranular $\gamma$ ' precipitates. 
The weld solidification sequence of 282 alloy can be determined by both microstructure characterization and non-equilibrium (Scheil) solidification simulations. While there are simplifying assumptions within the Scheil equation, it has been shown to be a good predictor of weld solidification in Ni-base alloys [9]. Scheil solidification calculations were performed with the Thermotech Ni-based Superalloys Database Version 8.0 (TTNi8). The non-equilibrium solidus temperature $\left(T_{\text {sol }}\right)$ was selected at a fraction solid $\left(f_{\text {sol }}\right)$ of 0.99 , which is customarily selected for Scheil simulations of weld solidification. Carbon was selected as a fast-diffusing element, which signifies that it exhibits complete diffusion in the solid during Scheil solidification.

The calculated Scheil solidification results are provided in Table II. Weld solidification behavior is controlled by solute redistribution. According to the calculations, Mo, Ti, C, and B segregate strongly to the interdendritic regions during solidification. Thus, it can be expected that (Ti,Mo)rich $\mathrm{MC}$ is formed during weld solidification. The Scheil calculations also predicted the formation of Mo-rich phases such as $\mathrm{M}_{6} \mathrm{C}$, $\sigma$ phase (also $\mathrm{Cr}$-rich), and $\mathrm{M}_{3} \mathrm{~B}_{2}$. There has been no experimental evidence of $\mathrm{M}_{6} \mathrm{C}$ in as-solidified 282 weld metal. There has also been no experimental evidence of $\sigma$ phase or other topologically closed-packed (TCP) phases. As such, further Scheil calculations were conducted with these additional phases restricted from forming. The last liquid to solidify is expected to be significantly enriched in B since the approximate partition coefficient $(\mathrm{k})$ of $\mathrm{B}$ according to the Ni-B binary phase diagram is 0.04 . Thus, if the terminal liquid is enriched in $\mathrm{B}$, there is expected to be enhanced grain boundary wetting and the possible formation of borides or B-rich particles during terminal solidification. Increasing $\mathrm{B}$ from 0.003 to $0.005 \mathrm{wt} \%$ in 282 alloy was shown to either promote the formation of the $\mathrm{M}_{3} \mathrm{~B}_{2}$ phase or widen the Scheil solidification range. When $\mathrm{M}_{3} \mathrm{~B}_{2}$ was predicted to form during terminal solidification, it did not widen the Scheil solidification range $(\Delta \mathrm{Ts})$ appreciably. However, $\Delta$ Ts predictions increased by $16^{\circ} \mathrm{C}$ when $\mathrm{M}_{3} \mathrm{~B}_{2}$ was restricted from forming. The non-equilibrium solidus of $\sim 1170^{\circ} \mathrm{C}$ that was experimentally determined by other researchers [11] is in good agreement with the calculated $\mathrm{T}_{\text {sol }}$ when phases were restricted. Calculations of the production heat compositions evaluated in this study were shown to slightly magnify this quantitative effect of $\mathrm{B}$. The calculated $\mathrm{T}_{\text {sol }}$ of the $0.005 \mathrm{wt} \% \mathrm{~B}$ heat was $22{ }^{\circ} \mathrm{C}$ lower than that for the $0.003 \mathrm{wt} \% \mathrm{~B}$ heat. This slightly larger difference can be attributed only to the minor heat-to-heat differences in the concentrations of the other alloying elements. In any case, a $\sim 20{ }^{\circ} \mathrm{C}$ increase in $\Delta \mathrm{Ts}$ could account for the observed differences in Varestraint crack lengths, especially if it is related to a lower solidus.

Table II. Scheil Solidification Results for 282 Alloy.

\begin{tabular}{|c|c|c|c|c|}
\hline $\begin{array}{l}\text { Composition } \\
(w t \%)\end{array}$ & $\begin{array}{r}\mathbf{T}_{\text {liq }} \\
\left({ }^{\circ} \mathrm{C}\right)\end{array}$ & $\begin{array}{c}T_{\text {sol }} \\
\left(f_{\text {sol }}=0.99\right) \\
\left({ }^{\circ} \mathrm{C}\right)\end{array}$ & $\begin{array}{l}\Delta \mathrm{Ts} \\
\left({ }^{\circ} \mathrm{C}\right)\end{array}$ & Solidification Phases \\
\hline \multicolumn{5}{|c|}{ All Phases Allowed } \\
\hline $282 *-0.005 \mathrm{~B}$ & 1353 & 1204 & 149 & $\gamma+\mathrm{MC}+\mathrm{M}_{6} \mathrm{C}+\sigma+\mathrm{M}_{3} \mathrm{~B}_{2}$ \\
\hline $282 *-0.003 \mathrm{~B}$ & 1353 & 1206 & 147 & $\gamma+\mathrm{MC}+\mathrm{M}_{6} \mathrm{C}+\sigma$ \\
\hline \multicolumn{5}{|c|}{ Phases Restricted to: Liquid, FCC, MC, $\mathbf{M}_{3} \mathrm{~B}_{2}$} \\
\hline $282 *-0.005 \mathrm{~B}$ & 1353 & 1172 & 181 & $\gamma+\mathrm{MC}+\mathrm{M}_{3} \mathrm{~B}_{2}$ \\
\hline $282 *-0.003 \mathrm{~B}$ & 1353 & 1172 & 181 & $\gamma+\mathrm{MC}+\mathrm{M}_{3} \mathrm{~B}_{2}$ \\
\hline \multicolumn{5}{|c|}{ Phases Restricted to: Liquid, FCC, MC } \\
\hline $282 *-0.005 \mathrm{~B}$ & 1353 & 1152 & 201 & $\gamma+\mathrm{MC}$ \\
\hline $282 *-0.003 \mathrm{~B}$ & 1353 & 1168 & 185 & $\gamma+\mathrm{MC}$ \\
\hline
\end{tabular}

*Ni-20Cr-10Co-8.5Mo-2.1Ti-1.5Al-0.06C 


\section{Effect of Postweld Heat Treatment on Weld Metal Microstructure}

During a standard postweld SA at $2075^{\circ} \mathrm{F}\left(1135^{\circ} \mathrm{C}\right)$ for 30 minutes, 282 weld metal achieves only partial recrystallization as some initial solidification grain boundaries are left intact. Upon postweld age-hardening at $1850^{\circ} \mathrm{F}\left(1010^{\circ} \mathrm{C}\right)$ above the $\gamma^{\prime}$ solvus, $\mathrm{Cr}$-rich $\mathrm{M}_{23} \mathrm{C}_{6}$ carbides are precipitated along solidification grain boundaries in the weld metal. However, significantly more precipitation of "blocky" $\mathrm{M}_{23} \mathrm{C}_{6}$ is observed along recrystallized grain boundaries, as shown in Figure 5. This finding suggests that weld metal that has been postweld SA prior to age hardening can be expected to offer better elevated-temperature ductility and creep strength since $\mathrm{M}_{23} \mathrm{C}_{6}$ carbides, and their morphology, are associated with those properties in 282 alloy. Upon age-hardening at $1450^{\circ} \mathrm{F}\left(788^{\circ} \mathrm{C}\right)$, precipitation of $\gamma^{\prime}$ occurs, which is the main phase for creep strengthening. There has also been evidence of MC carbides partially transforming to $\mathrm{M}_{23} \mathrm{C}_{6}$, $\mathrm{M}_{6} \mathrm{C}$, and $\gamma^{\prime}$ during this step of the heat treatment. The fine $\gamma^{\prime}$ precipitates (Figure 5) normally have a size similar to that typically observed in age-hardened base material. The $\gamma^{\prime}$ precipitates are found throughout the intragranular regions and at the grain boundaries of the weld metal. The average size of the $\gamma^{\prime}$ was seen to increase nearer to the grain boundaries. $\gamma^{\prime}$ precipitation that extends to the grain boundaries in the weld metal is considered to be a positive feature of 282 alloy since $\gamma^{\prime}$-free zones near grain boundaries would have a negative effect on creep strength. The recently developed $\gamma^{\prime}$-strengthened alloy $740 \mathrm{H}$ has been plagued by the formation of $\gamma^{\prime}$-free zones in the weld metal, even after postweld heat treatment, resulting in a $\sim 30 \%$ reduction in creep strength compared to the base metal [11, 12]. As a result, 282 alloy is being considered as a weld filler metal for joining this alloy [11].
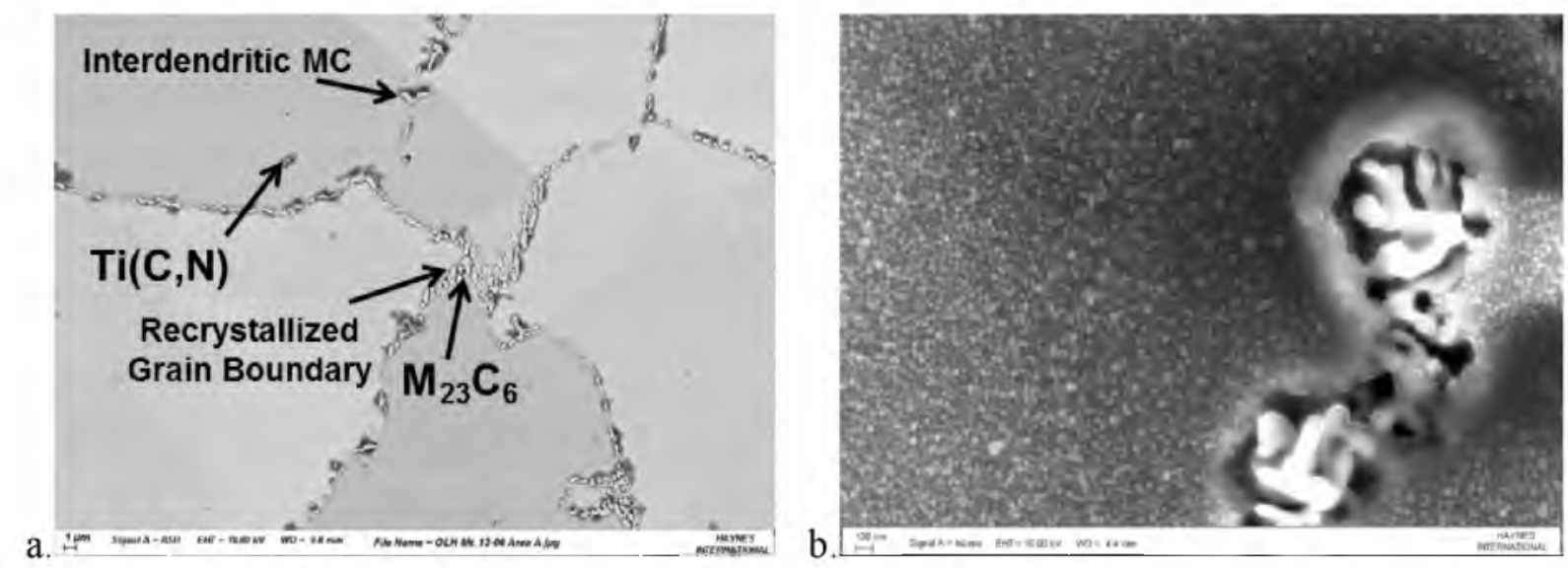

Figure 5. SEM micrographs of 282 weld metal in the postweld annealed + age-hardened condition. Carbides are shown in the left micrograph (5a). Fine $\gamma^{\prime}$ precipitates are shown in the right micrograph $(5 \mathrm{~b})$; note that grain boundary carbides were removed by the $\gamma^{\prime}$ etchant.

\section{$\underline{\text { Hot-Ductilitv Test Results }}$}

The hot-ductility test results for 282 alloy in the age-hardened condition are shown in Figure 6. As shown, several on-heating and on-cooling tests were performed in order to determine susceptibility to HAZ liquation cracking. A steep decrease in on-heating ductility was exhibited between $1191{ }^{\circ} \mathrm{C}(73 \% \mathrm{RA})$ and $1204^{\circ} \mathrm{C}(17 \% \mathrm{RA})$. This steep decrease is typical on-heating behavior for Ni-base alloys and represents the onset of melting within the microstructure, usually in the form of grain boundary liquid films [9]. Upon heating to higher temperatures, a nilductility temperature (NDT) of $1260^{\circ} \mathrm{C}$ was determined. The NDT represents the temperature where ductility is zero, usually as a result of continuous liquid films at the grain boundaries. The 
NST was determined to be $1321^{\circ} \mathrm{C}$ from an average of three samples. In this location, the sample experiences bulk melting and re-solidification. The NDT and NST values differ from those determined in a published hot-ductility study of 282 alloy [13]. However, direct comparison is not feasible since the heat treatment condition, test sample geometry, and testing techniques were all considerably different.

The NST was used to determine an appropriate peak temperature for on-cooling tests. Ideally, on-cooling tests would be conducted with a peak temperature at the NST; however, this is often not possible due to sample instability at temperatures near the NST. Initially, tests were conducted with a peak temperature of $1301{ }^{\circ} \mathrm{C}$, but this caused cracking of the sample at the peak temperature prior to cooling to the test temperature. Subsequently, tests were conducted with a slightly lower peak temperature of $1288^{\circ} \mathrm{C}$, which proved to be a more stable temperature for conducting the on-cooling tests. Using this peak temperature about halfway between the NDT and NST still represented a location within the partially melted zone near the weld interface. Since HAZ liquation cracking susceptibility is a function of the peak temperature within the $\mathrm{HAZ}$, it is important that this temperature be related to the on-cooling hot-ductility behavior. With this peak temperature, ductility was seen to recover to similar values obtained for onheating tests. A small amount of ductility, $3 \% \mathrm{RA}$, was recovered at $1232{ }^{\circ} \mathrm{C}$. Upon cooling to $1218^{\circ} \mathrm{C}, 28 \% \mathrm{RA}$ was achieved. As such, the ductility recovery temperature (DRT) is approximated to be within this temperature range, which represents a near immediate recovery in ductility. This finding was substantiated by testing at lower temperatures of $1204{ }^{\circ} \mathrm{C}$ and $1149^{\circ} \mathrm{C}$ where approximately $75 \% \mathrm{RA}$ was achieved. The difference between the NST and DRT is known as the liquation cracking temperature range (LCTR). As such, the LCTR range for 282 alloy in the age-hardened condition is $\sim 90^{\circ} \mathrm{C}$. Based on comparable data for Waspaloy $-209^{\circ} \mathrm{C}$ [14] and $718-103{ }^{\circ} \mathrm{C}$ [15] tested in a similar manner, 282 alloy appears to have better HAZ liquation cracking resistance than these alloys. In any case, the narrow LCTR of 282 alloy in the age-hardened condition can be attributed to rapid re-solidification of the intergranular metastable liquid upon cooling. Overall, the hot-ductility behavior of age-hardened 282 alloy suggests that it has excellent resistance to HAZ liquation cracking.

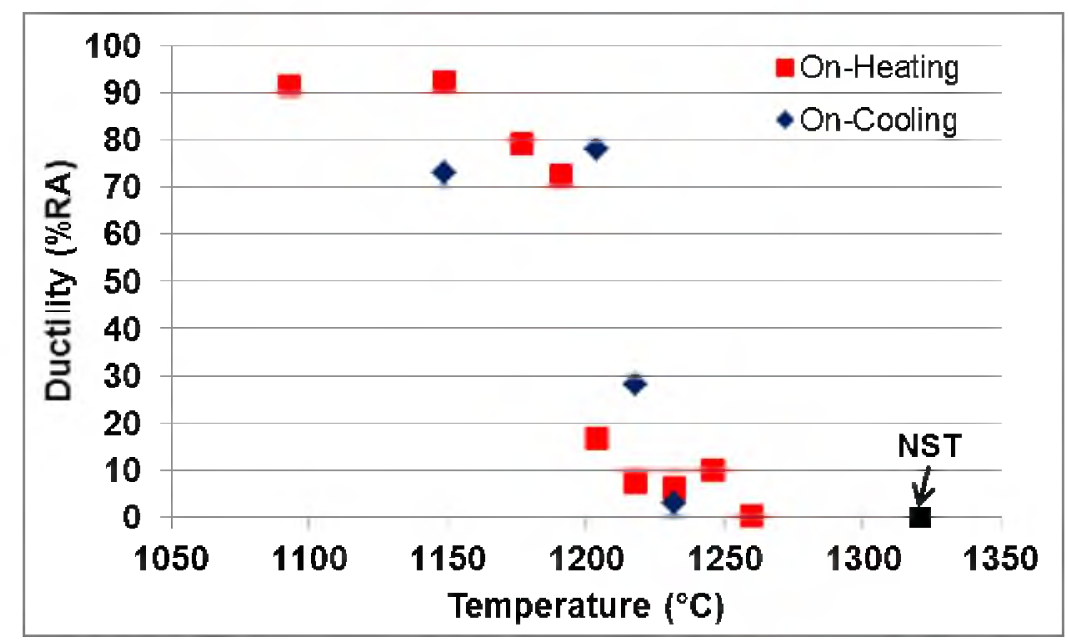

Figure 6. Hot-ductility test results for 282 alloy in the age-hardened condition.

\section{$\underline{\text { HAZ Microstructure Evolution }}$}

By analyzing the microstructures of hot-ductility test samples, the HAZ microstructure evolution could be determined for 282 alloy in the age-hardened condition. An understanding of the HAZ 
microstructure evolution is key to understanding the on-heating liquation mechanism and HAZ liquation cracking susceptibility. Microstructure evolution in the HAZ of age-hardened 282 alloy proceeds first with dissolution of the fine $\gamma^{\prime}$ precipitates. The darker and lighter etched regions in the optical micrograph shown in Figure 7 are evidence of the presence and absence of $\gamma^{\prime}$ precipitates, respectively. The lighter region closer to the fracture surface suggests that $\gamma^{\prime}$ dissolution had occurred in this region of the sample. The peak temperature in the region of the sample where $\gamma^{\prime}$ did not dissolve would have been lower than at locations closer to the middle of the sample due to the thermal gradient along the length of the sample. The sharp interface between the dark and light etched regions indicates that $\gamma^{\prime}$ dissolution proceeded over a narrow temperature range. The indirect evidence of $\gamma^{\prime}$ dissolution was confirmed by SEM analysis (Figure 8a) and has been observed in the HAZ of actual welds. Since $\gamma^{\prime}$ dissolution occurred at relatively low temperatures well away from the hot-ductility fracture surfaces, it is not expected to have played a significant role in the on-heating liquation mechanism. Since the region of the HAZ closest to the weld experiences a peak temperature approaching the nominal liquidus of 282 alloy $\left(1377^{\circ} \mathrm{C}\right)$, it reasons that there would be dissolution of the $\gamma^{\prime}$ phase at temperatures well above its solvus of $\sim 1000^{\circ} \mathrm{C}$. As such, $\gamma^{\prime}$ dissolution establishes the temperature in this region of the sample to be at least $1000^{\circ} \mathrm{C}$.

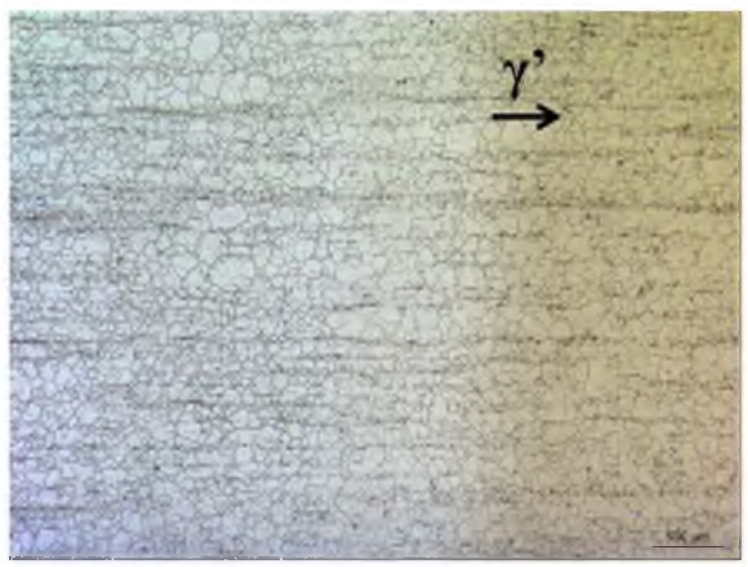

Figure 7. Representative optical micrograph of hot-ductility test sample at a location well away from the fracture surface. The sample was etched to reveal the presence of $\gamma^{\prime}$ precipitates.
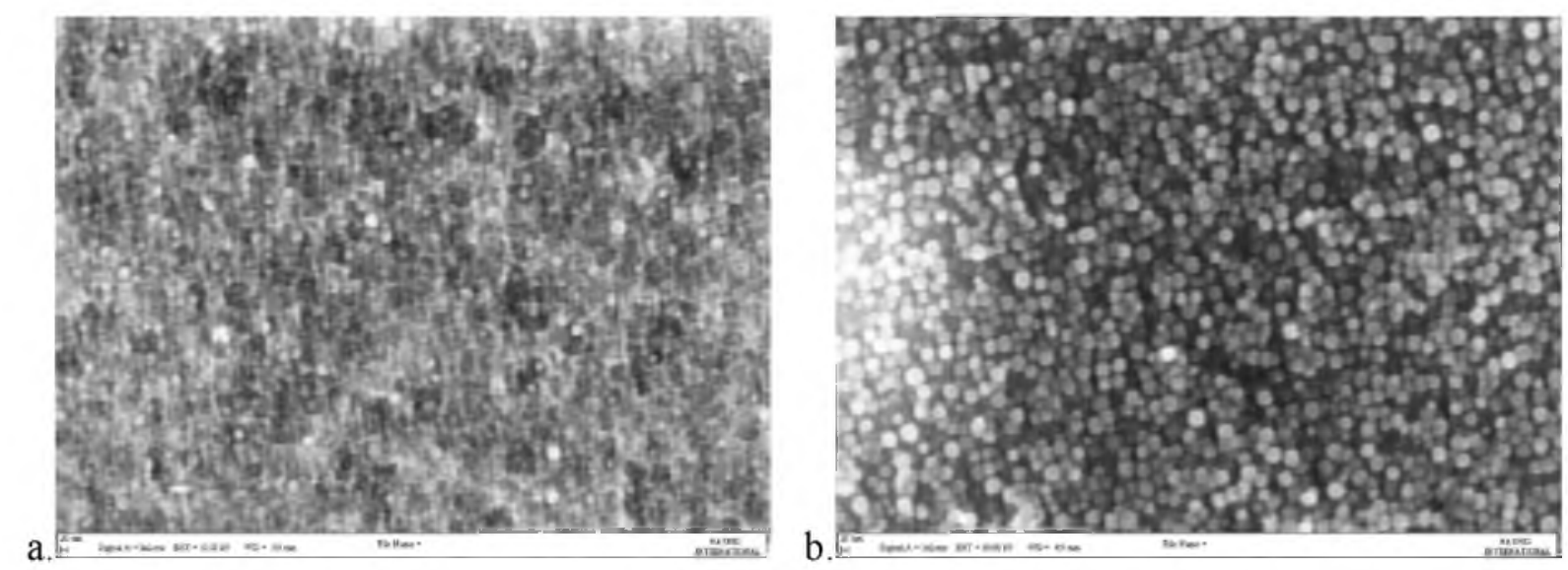

Figure 8. SEM micrographs of hot-ductility test sample etched to reveal the presence of $\gamma^{\prime}$ precipitates. The left micrograph (8a) exhibits $\gamma^{\prime}$ dissolution. Spherical $\gamma^{\prime}$ precipitates are visible in the right micrograph ( $8 \mathrm{~b}$ ) due to a slightly lower peak temperature at a location $\sim 50 \mu \mathrm{m}$ from the location of the left micrograph. 
At higher peak temperatures, there was evidence of instability of the $\mathrm{Cr}$-rich $\mathrm{M}_{23} \mathrm{C}_{6}$ carbides when examined in the SEM. In these locations, the Mo-rich particles and large primary (Ti,Mo)rich MC appeared to remain stable, as shown in Figure 9. Also apparent from optical metallography was evidence of liquated particles in relatively straight lines, possibly representing prior grain and twin boundaries in the microstructure that were left behind by migrating grain boundaries. Otherwise, it can be assumed that grain boundaries were pinned by the liquid films. Grain size measurements indicated that there was only a small amount of grain growth in this region with average grain size of ASTM No. 3.5 to 4.0.

In the region of the NDT sample heated to $1260^{\circ} \mathrm{C}$, there was no evidence of secondary carbides within the microstructure. Shown in Figure $9 \mathrm{a}$ is the microstructure at a location near to the NDT fracture surface that exhibited evidence of liquation in the form of continuous liquid films at the grain boundaries. Secondary cracking along the grain boundaries is also evident. At higher magnifications, the widened liquated grain boundaries appear to be free of any secondary particles. However, at temperatures just below $1260^{\circ} \mathrm{C}$, grain boundary precipitates were still evident (Figure 9b). These were identified as Cr-rich carbides, presumably $\mathrm{M}_{23} \mathrm{C}_{6}$, by SEMEDS analysis. While there is the possibility that these carbides were formed on-cooling, they were not present along the grain boundaries nearer to the fracture surface. The grain boundaries were also more heavily decorated further from the fracture surface. This evidence suggests that the grain boundaries did not exhibit continuous liquation until a temperature of $\sim 1250{ }^{\circ} \mathrm{C}$.
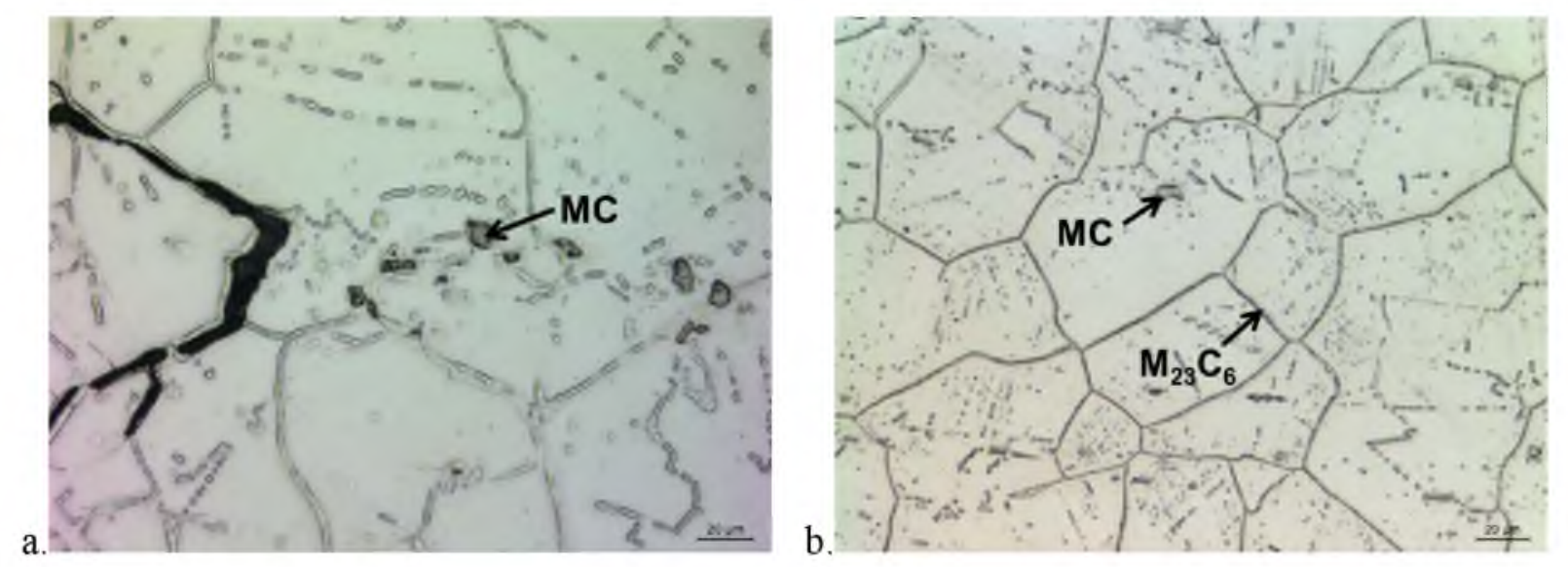

Figure 9. Optical micrographs of NDT sample. The left micrograph (9a) near the fracture surface exhibits evidence of widened liquated grain boundaries without secondary precipitates. In the right micrograph $(9 \mathrm{~b})$ slightly further from the fracture surface, grain boundary precipitates are evident.

Instability of the large primary $(\mathrm{Ti}, \mathrm{Mo})$-rich $\mathrm{MC}$ carbides was not evident until temperatures above the NDT. Their stability indicates that they did not play a role in the on-heating liquation mechanism. This can be expected of rather large primary carbides that formed during initial ingot solidification. At the very highest temperatures approaching the NST, eutectic melting of the MC carbides was observed (Figure 10b). The large $\mathrm{Ti}(\mathrm{C}, \mathrm{N})$ particles were stable to the highest temperatures. 

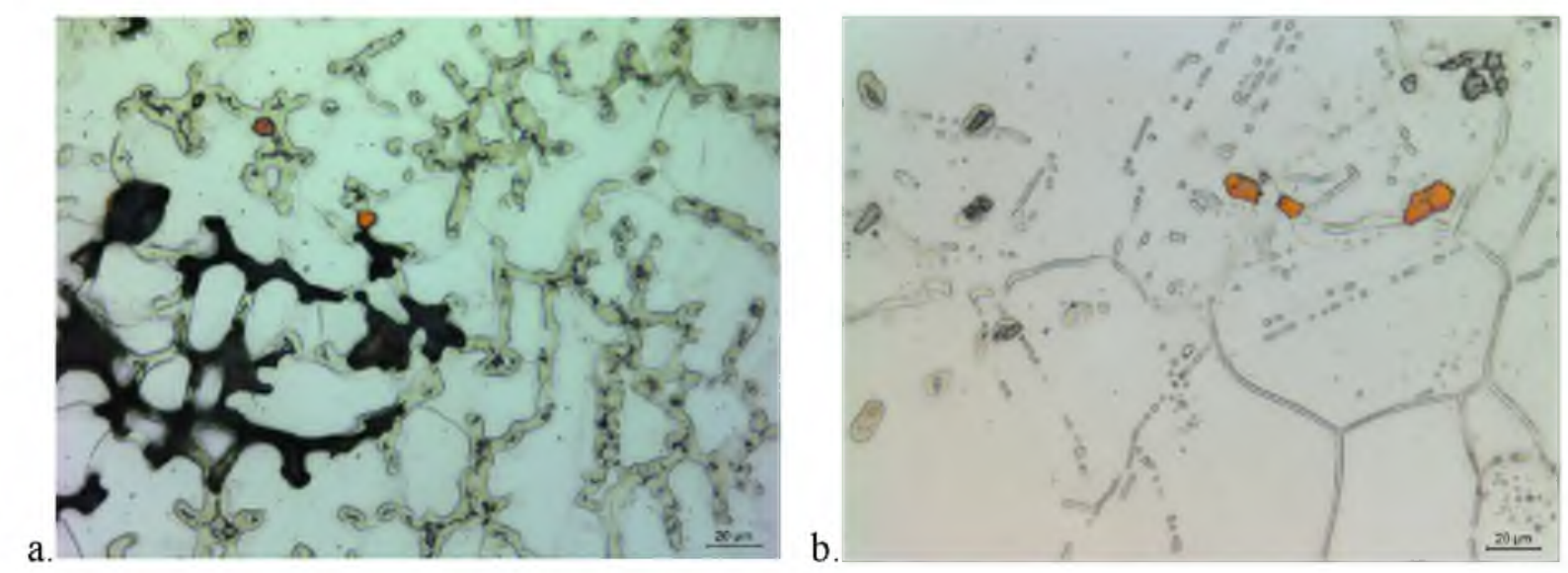

Figure 10. Optical micrographs of NST sample. The left micrograph (10a) at the fracture surface exhibits bulk melting and re-solidification. The right micrograph (10b) at a lower peak temperature further from the fracture surface exhibits partial melting of primary $\mathrm{MC}$ carbides The large $\operatorname{Ti}(\mathrm{C}, \mathrm{N})$ particles (shown orange) were stable to the highest temperatures.

The most plausible explanation for the observed liquation is the constitutional liquation mechanism first detailed by Pepe and Savage [16]. In this mechanism, a secondary phase reacts with the surrounding matrix to form a solute-rich liquid at temperatures well below the equilibrium solidus of the alloy. For constitutional liquation to be operative for a particular secondary phase, the temperature must be above the solvus of that phase. This mechanism also requires the intersection of the locally melted regions with (migrating) grain boundaries in order for the liquid to penetrate and wet the boundaries. The $\mathrm{M}_{23} \mathrm{C}_{6}$ carbides are readily formed by heat treatment at $1010^{\circ} \mathrm{C}$, a temperature slightly above the $\gamma^{\prime}$ solvus, and the grain boundaries of 282 alloy in the proper age-hardened condition are heavily decorated with these carbides. So in the age-hardened condition, $\mathrm{M}_{23} \mathrm{C}_{6}$ carbides are preferentially located along the grain boundaries to cause penetration and wetting. Under slow heating rate conditions, dissolution of $\mathrm{M}_{23} \mathrm{C}_{6}$ would indeed be expected above its solvus. However, due to the relatively fast heating rate in both a HAZ thermal cycle and hot-ductility test, it is less likely that these carbides dissolve completely to go back into solid solution at temperatures above their solvus since there is not sufficient time for complete dissolution. Accordingly, due to the rapid heating rates, localized melting was possible at temperatures significantly below the equilibrium solidus of $1317^{\circ} \mathrm{C}$. Based on hot-ductility data, the onset of melting occurred above the typical solution annealing range of 282 alloy $\left(1121-1149^{\circ} \mathrm{C}\right.$ ). While the $\mathrm{M}_{23} \mathrm{C}_{6}$ solvus in 282 alloy is unknown, based on experience it is known that they readily dissolve during solution annealing at temperatures above $1121^{\circ} \mathrm{C}$. Based on thermodynamic calculations of the nominal 282 alloy composition, the $\mathrm{M}_{23} \mathrm{C}_{6}$ solvus is predicted to be $1032{ }^{\circ} \mathrm{C}$. Regardless of the precise solvus temperature, considerable superheating is usually required in the HAZ region in order to overcome the inherent kinetic barrier against particle dissolution [17]. Required superheating of $\sim 150^{\circ} \mathrm{C}$ would not be unreasonable to expect. Even in the event of complete dissolution, the soluteenriched regions that were generated would have promoted subsequent liquation at higher temperatures. The coincidence of $\mathrm{M}_{23} \mathrm{C}_{6}$ instability and Mo-rich particle stability was corroborated by thermodynamic calculations that indicated the solvus of $M_{6} C$ and $M_{3} B_{2}$ to be $1182{ }^{\circ} \mathrm{C}$ and $1260^{\circ} \mathrm{C}$, respectively, which is much higher than that predicted for $\mathrm{M}_{23} \mathrm{C}_{6}$. The predicted solvus for the (Ti,Mo)-rich $\mathrm{MC}$ carbides $\left(1290^{\circ} \mathrm{C}\right)$ was higher than the calculated equilibrium solidus $\left(1260^{\circ} \mathrm{C}\right)$. 
Mo-rich phases, either $\mathrm{M}_{6} \mathrm{C}$ identified by research at Haynes or a boride, such as $\mathrm{M}_{5} \mathrm{~B}_{3}$, identified by other researchers [18], have been observed in 282 alloy in the age-hardened condition. While there is presumably a minor amount of borides present in the age-hardened condition, there is simply not enough boron available for a significant amount of these particles to form during the two-step age-hardening heat treatment. Thermodynamic calculations indicate that if all of the available boron was contained within boride phases, the maximum volume fraction of the boride phases in 282 alloy would be approximately 0.0007 . Comparatively, the predicted volume fraction of $\mathrm{M}_{23} \mathrm{C}_{6}$ carbides is 0.014 , or approximately $20 \mathrm{x}$ that achievable by borides. Furthermore, the formation of Mo-rich borides would not preclude the formation of Mo-rich carbides as there would be plenty of additional Mo and $\mathrm{C}$ available; thermodynamics predicts a significantly greater amount of $\mathrm{M}_{6} \mathrm{C}$ to form than $\mathrm{M}_{3} \mathrm{~B}_{2}$. As such, it is more likely that carbide liquation would account for the rather wide and continuous liquation of grain boundaries that was observed. However, it is assumed that "free" boron at the grain boundaries plays a secondary role in the liquation mechanism. Boron is known to segregate to grain boundaries and enhance the wetting of grain boundaries by acting as a surface energy depressant. Since the $\mathrm{M}_{23} \mathrm{C}_{6}$ carbides likely contain a small amount of boron, it would also be released as they dissolve. In fact, 282 alloy was found to have improved HAZ liquation cracking resistance when laser beam welded in the annealed condition compared to the age-hardened condition [18]. While the authors solely attributed the cracking to constitutional liquation of $M_{5} B_{3}$ and the subsequent improvement to solutionization of these borides, it is likely that a large share of the improvement resulted from solutionizing the $\mathrm{M}_{23} \mathrm{C}_{6}$ carbides at the grain boundaries prior to welding. Certainly, a preweld heat treatment designed to solutionize $\mathrm{M}_{23} \mathrm{C}_{6}$ means that these carbides would not be available to contribute to $\mathrm{HAZ}$ liquation. It is possible that the initial decrease in ductility to very low, but not zero, values in this study was associated with $\mathrm{M}_{23} \mathrm{C}_{6}$ liquation, and that nil ductility was eventually reached upon dissolution/liquation of Mo-rich particles. A different $\mathrm{HAZ}$ liquation mechanism for 282 alloy in the annealed condition would be expected since $\mathrm{M}_{23} \mathrm{C}_{6}$ and other secondary particles should not be present in appreciable amounts. However, HAZ liquation is expected at temperatures below the nominal solidus in almost any multi-component alloy. Further investigation of HAZ microstructure evolution and liquation cracking in the age-hardened and annealed conditions is ongoing.

\section{Summary and Conclusions}

Building upon the prior studies to evaluate the strain-age cracking resistance of 282 alloy [6, 7], the three main weld cracking mechanisms in $\gamma^{\prime}$-strengthened Ni-base alloys have now been investigated for 282 alloy. The following conclusions can be drawn from the present work:

1. Based on Varestraint test results, 282 alloy exhibits excellent solidification cracking resistance for a high-temperature Ni-base alloy. The results suggest that the weld solidification cracking resistance of 282 alloy is sensitive to higher levels of boron and weld restraint. However, the nominal boron heat exhibited better solidification cracking resistance than R-41, Waspaloy, and 718 alloys.

2. The weld metal microstructure was characterized in both the as-welded and postweld heat treated conditions. The as-solidified weld metal microstructure of 282 alloy mainly consists of fcc $\gamma$ phase with discrete (Ti,Mo)-rich $\mathrm{MC}$ carbide formed along the solidification grain boundaries. In addition, intergranular $\mathrm{Cr}$-rich $\mathrm{M}_{23} \mathrm{C}_{6}$ carbides and intragranular $\gamma$ ' precipitates were identified in the as-welded condition. Microstructures subjected to a postweld heat 
treatment exhibited significant grain boundary $\mathrm{M}_{23} \mathrm{C}_{6}$ precipitation and $\gamma^{\prime}$ precipitates throughout the intragranular regions extending to the grain boundaries.

3. Hot-ductility testing of 282 alloy in the age-hardened condition revealed a near immediate recovery in on-cooling ductility and a relatively narrow LCTR when compared to Waspaloy and 718 alloys. This finding suggests that it has excellent resistance to HAZ liquation cracking in the age-hardened condition.

4. The HAZ microstructure evolution of age-hardened 282 alloy was determined based on characterization of on-heating hot-ductility microstructures. Dissolution of $\gamma^{\prime}$ precipitates was observed at on-heating peak temperatures well below the NDT. The on-heating liquation mechanism was mainly attributed to constitutional liquation associated with dissolution of $\mathrm{Cr}$ rich $\mathrm{M}_{23} \mathrm{C}_{6}$ carbides. The dissolution/liquation of Mo-rich particles and segregation of $\mathrm{B}$ to the grain boundaries were also identified as possible contributing factors.

\section{Acknowledgments}

The author would like to thank Haynes International metallographic technicians Mark Richeson and John Cotner for their outstanding efforts

\section{References}

1. L. M. Pike, "HAYNES® 282® Alloy - A New Wrought Superalloy Designed for Improved Creep Strength and Fabricability," ASME Turbo Expo 2006, GT2006-91204 (2006).

2. L. M. Pike, "Development of a Fabricable Gamma-Prime $\left(\gamma^{\prime}\right)$ Strengthened Superalloy," Superalloys 2008, ed. R. C. Reed et al. (Hoboken, NJ: John Wiley \& Sons, Inc., TMS, 2008), 191-200.

3. AWS A3.0M/A3.0:2010, Standard Welding Terms and Definitions (Miami, FL: American Welding Society, 2009), 47.

4. Haynes International, Inc., HAYNES® $282 \circledR$ Alloy, http://www.haynesintl.com/pdf/h3173.pdf (2008), 20-21.

5. J. L. Caron and L. M. Pike, "Weldability of HAYNES 282 Superalloy After Long-Term Thermal Exposure," EURO Superalloys 2014, Accepted for Publication.

6. D. A. Metzler, "A Gleebleß-based Method for Ranking the Strain-Age Cracking Susceptibility of Ni-Based Superalloys," Welding Journal, 87 (2008), 249-s-256-s.

7. D. A. Metzler, "Strain-Age Cracking Susceptibility of Ni-Based Superalloys as a Function of Strain Rate, Temperature, and Alloy Composition," Welding Journal, 91 (2012), 163-s-168-s.

8. C. D. Lundin et al., "The Varestraint Test," Welding Research Council Bulletin, 280 (1982), 119.

9. J. N. DuPont, J. C. Lippold, and S. D. Kiser, Welding Metallurgy and Weldability of NickelBase Alloys, (Hoboken, NJ: John Wiley \& Sons, Inc., 2009). 
10. J. F. Radavich, "Electron Metallography of Alloy 718," Superalloys 718, 625, 710 and Various Derivatives, ed. E. A. Loria, 17-26 (1997).

11. D. C. Tung and J. C. Lippold, "Weld Solidification Behavior of Ni-Base Superalloys for Use in Advanced Supercritical Coal-Fired Power Plants," Superalloys 2012, ed. E. S. Huron et al. (Hoboken, NJ: John Wiley \& Sons, Inc., TMS, 2012), 563-567.

12. D. H. Bechetti, "Microstructural Evolution and Creep Rupture Behavior of INCONEL® Alloy $740 H ®$ Fusion Welds," Ph.D. Dissertation, Lehigh University, (2013).

13. J. Andersson, G. Sjöberg, and M. Chaturvedi, "Hot Ductility Study of HAYNES® $282 ®$ Superalloy," 7th International Symposium on Superalloy 718 and Derivatives, ed. E. A. Ott et al. (TMS, 2010), 539-554.

14. M. Qian and J. C. Lippold, "Effect of Multiple Postweld Heat Treatment Cycles on the Weldability of Waspaloy," Welding Journal, 81 (2002), 233s-238s.

15. M. Qian and J. C. Lippold, "Liquation Phenomena in the Simulated Heat-Affected Zone of Alloy 718 after Multiple Postweld Heat Treatment Cycles," Welding Journal, 82 (2003), 145s150 s.

16. J. J. Pepe and W. F. Savage, "Effects of Constitutional Liquation in 18-Ni Maraging Steels," Welding Journal, 46 (1967), 411s-4422-s.

17. Ø. Grong, Metallurgical Modelling of Welding, Second Edition, ed. H. K. D. H. Bhadeshia, (London, UK: The Institute of Materials, 1997).

18. L. O. Osoba, R. G. Ding, and O. A. Ojo, "Improved Resistance to Laser Weld Heat-Affected Zone Microfissuring in a Newly Developed Superalloy HAYNES 282," Metallurgical and Materials Transactions A, 43 (2012), 4281-4295. 